\title{
Examination of Colorfastness to Laundering of Naturally Dyed Fabrics using Contact Dyeing Method with Blueberries
}

\author{
Lauren Barker, Ui-Jeen Yu*, and Paulina Wietocha \\ Illinois State University, USA
}

*Corresponding author: Ui-Jeen Yu, Associate Professor, Dept. of Family and Consumer Sciences, Illinois State University, USA.

\author{
Received Date: May 17, 2019 \\ Published Date: May 23, 2019
}

\begin{abstract}
Use of the contact dyeing method and natural mordants may have potential for reducing wastewater and developing a more sustainable method for natural dyeing. However, few studies have investigated colorfastness of naturally dyed fabrics using a contact dyeing method. Thus, the purpose of this study was to examine colorfastness to laundering of naturally dyed fabrics using contact dyeing and a natural mordant in relation to different mordant concentrations, mordanting procedures, and heating times. Mashed blueberries were sprayed on bleached cotton fabrics. Vinegar, a mordant, was applied in different concentrations: 25,50 , or $100 \%$ on the fabric. Mordanting treatment was applied in pre-, consecutive-, or postdyeing procedures. After dyeing, specimens were heated in a microwave for 10, 15, or 20 minutes and dried before colorfastness testing. AATCC 61 Colorfastness to laundering was conducted. Results indicated extended heat exposure, and pre-and post-mordanting procedures yielded better colorfastness to laundering. However, overall colorfastness to laundering of the contact-dyed cotton fabrics was poor to moderate, below acceptable performance standards for apparel products. Further research on different dye substances, natural mordants, heating methods, and heating times is needed to improve colorfastness of contact-dyed fabrics to laundering as well as to expand the use of sustainable contact-dyeing for consumers and the environment.
\end{abstract}

Keywords: Contact-dyeing method; Colorfastness to laundering; Naturally dyed cotton fabric using blueberries

\section{Introduction}

Compared to synthetic dyes, natural dyes produce a limited variety of colors with soft, irregular shadings [1]. Natural dyes are restricted to artisan, craftsmanship, or small scale mainly because colorfastness of natural dyes is not like those for chemical dyes in large-scaled dyeing techniques producing moderate to excellent colorfastness. To improve colorfastness, natural dyes are still exclusively used with chemical mordants, commonly containing aluminum, which produce unsafe wastewater from the dyeing process [2]. A substantial amount of water is also wasted during the dyeing process, making the process of natural dyeing unsustainable.

The immersion dyeing method is a commonly used approach to natural dyeing by submerging fibers or fabrics directly in a dye concentration for a period of time with heat and mordant [3]. The immersion dyeing method generates excessive water consumption and water waste with dyes and toxic/chemical mordants that may negatively impact the environment. Use of the contact dyeing method and natural mordants may have potential for reducing wastewater and developing a more sustainable method for natural dyeing [3]. Contact dyeing, known as no pot dyeing, is an alternative immersion dyeing by creating bundles using natural materials and a low liquor ratio method. Kadolph SJ, et al. [3] suggest contact dyeing can be an eco-friendlier dyeing method with benefits of lower costs, less equipment, less labor, safer procedures, and smaller consumption of water than immersion dyeing. Although contact dyeing is suggested, the use of natural dyes through a contact dyeing method is still very limited, due to a lack of standard color retention and colorfastness. Compared with the contact dyeing method, the immersion dyeing method is more consistent and predictable in coloration when using proven recipes $[3,4]$.

Prior research identified different dyeing methods for natural dyes in relation to mordant concentration, mordanting procedures, and heating time influenced coloration and colorfastness $[1,4,5]$. 
However, few studies have investigated colorfastness of naturally dyed fabrics using a contact dyeing method with a natural mordant. Most of previous studies focused on examining colorfastness of naturally dyed fabrics using an immersion dyeing method. Thus, the purpose of this study was to examine colorfastness to laundering of naturally dyed fabrics using contact dyeing and a natural mordant in relation to different mordant concentrations, mordanting procedures, and times exposed to heat. Findings from this study would suggest more appropriate ways to enhance color retention and colorfastness of naturally dyed fabrics using a contact dyeing method.

\section{Literature Review}

\section{Contact dyeing methods}

For contact dyeing, dyers apply natural dyestuff and mordant directly to fabric, then heat, soften or fermentate, dry, and launder the fabric to improve dye fastness and color development. Steps in contact dyeing, suitable for laboratory or home dyeing, include 1) selecting materials to dye, such as textile, dyestuff, and mordant; 2) applying dyestuff through sprinkling or mashing; 3) applying liquid and/or dry mordant to create good color and pattern development; 4) creating and bagging the bundle to facilitate condensation of dyestuff and mordant into the fabric; 5) applying heat, microwaving, steaming, or baking to improve dye fastness and intensify depth of color; and 6) air drying the fabric before laundering and pressing [3]. Contact dyeing is waterless dying-an alternative method for natural dyes to counteract water waste. Contact dyeing still involves the use of natural, sustainable mordants, and heating/ microwaving/steaming/baking for improving color retention and colorfastness.

The contact dye method tends to result in random patterns or high concentrations of color in certain areas. These unique colors and/or patterns cannot be duplicated; thus, high in creativity. Preparation of the materials, such as using more than one dyestuff and/or mordant, variations among steps in the process, and the contact between the dye and textile may add to the freedom the dyer has when choosing the contact dye method.

\section{Factors influencing colorfastness of naturally dyed fabrics}

Previous studies indicate factors influencing colorfastness of naturally dyed fabrics using the immersion method are dyestuffs, types of fabrics, types of mordants, mordanting procedures (e.g. pre-, post-, concurrent, and non-mordanting), liquor ratios (dye or mordant concentration), dying/heating temperatures and times $[1,3,4,6,7]$. Li et al. [4] identified an increase in dye concentration and dyeing time improved color strength and colorfastness of cotton and wool fabrics dyed with persimmon dye. According to their study, color strength was improved by increases in dye (e.g., $100 \%$ persimmon juice powder) concentration from 50 to $200 \%$ and dyeing time from $30 \mathrm{~min}$. to $60 \mathrm{~min}$. especially with postmordanting on the cotton and wool fabrics after dyeing. They found addition of a chemical mordant (e.g. $5 \%$ FeSO $4 \cdot 7 \mathrm{H} 20$ ) on both fabrics and post-mordanting created stronger color appearance and colorfastness, compared with pre-mordanting, treating the fabrics in a mordant bath before dyeing, and meta-mordanting that concurrently used dyeing and mordanting in one bath. ShamesNateri, et al. [1] also found colorfastness to laundering/washing of nylon dyed with weld and pomegranate peel was better with premordanting, meta-mordanting, and post-mordanting procedures than non-mordanting procedures. Ganesan P, et al. [5] reported silk fabric dyed with natural dye from red prickly pear fruit had higher color strength and colorfastness to laundering in the post-mordanting with the use of synthetic mordant (e.g., copper sulphate) rather than pre-mordanting with the use of a natural mordant (myrobalan) along with a mordant concentration of $6 \%$ in all different dyeing methods. Interestingly, Ali NF, et al. [8] found a negative effect of mordant concentration on color strength of naturally dyed wool fabric with red prickly pear plants. The decreased color strength due to intense mordant concentrations may result from the strong affinity formed between the fabric and mordant, instead of formulating the affinity between the fabric and colorant facilitated through mordant.

Hou X, et al. [9] also examined colorfastness to laundering on the naturally dyed wool fabrics with orange peel as a new, natural dye stuff. They found wool fabrics were deeper and darker with direct dyeing methods with aluminum or iron mordants (premordant, one-bath and post-mordant rather than non-mordant), a higher dyeing temperature $\left(100^{\circ} \mathrm{C}\right.$ rather than 70 to $\left.90^{\circ} \mathrm{C}\right)$, a longer dyeing time (150min. rather than $120 \mathrm{~min}$. to $0 \mathrm{~min}$.), and higher orange peel extracts concentration [9]. They reported colorfastness to laundering of wool dyed with direct dyeing method and onebath mordanting with aluminum and with iron is Grade 3 and can be considered good [9]. Dyeing temperature and time, materialto-liquor ratio, mordants concentration, dye concentration, $\mathrm{pH}$ (concentration of acid/alkali), and common salt concentration have effects on color strength and colorfastness of cotton or wool fabrics using jackfruit wood extract [10] and indicaxanthin natural dyes [11].

Overall, factors influencing color strength and colorfastness of naturally dyed fabrics may vary mainly depending on types of natural dye stuffs (or extracted colorants), mordanting procedures, dyeing/heating temperature and time. These factors influencing coloration and colorfastness in contact dyeing method have not been previously identified. Hence, findings from this study may be useful guidelines about effects of these dyeing-related factors on coloration and colorfastness of contact-dyed fabrics.

\section{Methods}

\section{Specimens}

A plain woven, cotton fabric, purchased from Test fabrics Inc., was utilized for this study. The specifications for this fabric include $107 \mathrm{~g} / \mathrm{m} 2$ weight, 150 count, $0.356 \mathrm{~mm}$ thickness, and bleached to white, desized, and mercerized. A total of 80 specimens with a size of 2 in. $x$ in. were cut in the warp filling directions and prepared 
for contact dyeing. Cotton was selected for this study because it is a natural fiber and a renewable resource widely used for various types of products in apparel and interior furnishings [12,13].

\section{Dyeing procedures}

The dye substance was whole blueberries and the mordant was vinegar; these dye ingredients were used to make the experiment repeatable, sustainable, and easily achieved on various scales of production, due to their commonality and affordability. Most natural dyes are extracted from plant resources, such as roots, berries, bark, leaves, and wood [8]. Blueberries are a common vegetable dye, easily obtained. Despite Kadolph and Casselmans KD, et al. [3] suggestion to use copper as a mordant with fruit, vinegar is a more sustainable option, since copper compounds raise concerns about toxicity [2]. Mashed blueberries were sprayed on the specimens. Different mordant concentrations of 25,50 , and $100 \%$ were used, in addition to specimens with no mordant. When mordant was added, it was completed as a pre-dyeing treatment, consecutively with contact dyeing or a post-dyeing treatment. For each stage, the specimen was allowed to dry before moving to the next stage. After contact dyeing with different mordant applications, specimens were heated in a microwave for 10, 15, or $20 \mathrm{~min}$. and air-dried before AATCC 61 colorfastness testing.

\section{Test methods}

Colorfastness to laundering refers to the resistance of a material's color change, due to loss or transfer of its colorant to adjacent materials or both as a result of frequent laundering [14]. Color loss occurs when a dye molecule is weakly bonded to the fiber and loses its ability to remain bonded to the fiber [14]. Color transfer or bleeding occurs when dye molecules are rinsed off in water due to poor fiber-dye bond and stain another material in the water [13]. Using a Launder-Ometer, AATCC 61 evaluates color change of the material and color staining to other materials, resulting from detergent solution, abrasive action of five home laundering, and water for $45 \mathrm{~min}$. testing. AATCC 61-2003 Colorfastness to laundering was conducted to test naturally dyed fabrics through contact dyeing in relation to the different concentrations of mordant used, the mordanting stage in the dyeing process when the mordant was added, and the amount of time specimens spent heated during the dyeing process. Test No. 2A in AATCC 61 was conducted: $49^{\circ} \mathrm{C}$ or $120^{\circ} \mathrm{F}$ temperature, $150 \mathrm{~mL}$ total liquor volume, $0.15 \%$ detergent of total volume, and 50 steel balls. To evaluate color change, the Gray Scale for Color Change is used: Grade 5-negligible or no change as shown in Gray Scale Step 5 and Grade 1-severe color change in color equivalent to Gray Scale Step 1. To evaluate staining, the Gray Scale for Staining is used: Grade 5-negligible or no color transfer as shown in Gray Scale Step 5 and Grade 1-severe color transfer equivalent to Gray Scale Step 1. Color differences between the unwashed specimen and tested specimens were measured to determine color change. Color transfer from the specimen to multifiber test fabrics determines staining. Excellent colorfastness to laundering indicates the naturally dyed specimens through contact dyeing strongly retain color and withstand color change (loss) and staining (bleeding to other materials), due to frequent home laundering.

\section{Data analysis}

Using IBM SPSS Statistics 22.0, one-way between groups ANOVAs were conducted to examine how colorfastness to laundering differs, depending on different mordant concentrations, mordanting procedures, and heating times.

\section{Results}

Differences for colorfastness to laundering of the naturally-dyed specimens using contact dyeing were statistically examined by 1) different mordant concentrations-25, 50, and 100\%,2) different procedures-pre-, post-, concurrent, and non-mordanting, and 3) different heating times-10, 15, or $20 \mathrm{~min}$. Results indicated no significant differences in color change for the different mordant concentrations, $F(3,76)=.49, p>.05$. This indicates specimens with the three mordant concentrations of 25,50 , and $100 \%$ did not show color changes differently. The different mordant concentrations were not effective to reduce color loss and color change. Regarding the four different mordanting procedures, no significant differences in color change were observed, $F(3,76)=.065, p>.05$, indicating specimens with different procedures of pre-, post-, concurrent, and non-mordanting did not show differences in color changes. The different mordanting procedures did not generate differences in color change due to color loss (Table 1\&2).

Table 1: Mean scores and ANOVA of color change on cotton by four different mordant concentration: $0,25,50$, and $100 \%$.

\begin{tabular}{|c|c|c|c|c|c|}
\hline Mordant Concentration & $\mathbf{0 \%}(\mathbf{n}=\mathbf{8})$ & $\mathbf{2 5 \%}(\mathbf{n}=\mathbf{2 4})$ & $\mathbf{5 0 \%}(\mathbf{n}=\mathbf{2 4})$ & $\mathbf{1 0 0 \%}(\mathbf{n}=\mathbf{2 4})$ & $\mathbf{A N O V A}(\mathbf{n}=\mathbf{8 0})$ \\
\hline Mean & 2.63 & 2.5 & 2.67 & $\mathrm{~F}(3,76)=.49, \mathrm{p}>.05$ \\
\hline SD & 1.16 & 0.98 & 0.92 & 1.03 \\
\hline
\end{tabular}

Note: Grade 5-negligible or no color change as shown in Gray Scale Step 5, Grade 1-severe color change as shown in Gray Scale Step 1.

Table 2: Mean scores and ANOVA of color change on cotton by four different mordanting procedures: pre-, post-, concurrent, and non-mordanting procedures.

\begin{tabular}{|c|c|c|c|c|}
\hline Mordanting Procedures & $\begin{array}{c}\text { Non-Mordanting } \\
(\mathbf{n}=\mathbf{8})\end{array}$ & $\begin{array}{c}\text { Pre-Mordanting } \\
(\mathbf{n}=\mathbf{2 4})\end{array}$ & $\begin{array}{c}\text { Concurrent Mordanting } \\
\mathbf{( n = 2 4 )}\end{array}$ & $\begin{array}{c}\text { Post-Mordanting (n } \\
\mathbf{2} \mathbf{2 4})\end{array}$ \\
\hline Mean & 2.63 & 2.46 & 2.54 & 2.5 \\
\hline SD & 1.16 & 0.89 & 1.09 & $\mathrm{~F}(3,76)=.49, \mathrm{p}>.05$ \\
\hline
\end{tabular}

Note: Grade 5-negligible or no color change as shown in Gray Scale Step 5, Grade 1-severe color change as shown in Gray Scale Step 1. 
However, there were statistically significant differences in color change for the different times exposed to heat: $F(3,76)$ $=17.87, \mathrm{p}<.001$. The mean score for no heating $(\mathrm{M}=1.6, \mathrm{SD}=.88)$ was lower than those for $10 \mathrm{~min}$. heating $(\mathrm{M}=2.4, \mathrm{SD}=.75), 15 \mathrm{~min}$. heating $(M=2.76, S D=.70)$, and 20 min. heating $(M=3.356, S D=.73)$. Specimens exposed to longer heating tended to have less color loss when evaluating specimens by the gray scale for color change, indicating better colorfastness to laundering (Table 3).

Table 3: Mean scores and ANOVA of color change on cotton by four different times exposed to heat: 0, 10, 15, and $20 \mathrm{~min}$.

\begin{tabular}{|c|c|c|c|c|c|}
\hline Time Exposed to Heat & 0 Min. (N = 20) & 10 Min. (n= 24) & 15 Min. (n= 24) & 20 Min. (n= 24) & ANOVA (n= 80) \\
\hline Mean & 1.6 & 2.4 & 2.7 & 3.35 & $\mathrm{~F}(3,76)=17.87 .49, \mathrm{p}<.001^{* * *}$ \\
\hline SD & 0.88 & 0.75 & 0.7 & 0.73 & \\
\hline
\end{tabular}

Note: Grade 5-negligible or no color change as shown in Gray Scale Step 5, Grade 1-severe color change as shown in Gray Scale Step 1.

For staining on cotton, no significant differences were detected by the different mordant concentrations, $\mathrm{F}(3,76)=1.50, \mathrm{p}>.05$. This indicates specimens with the three mordant concentrations of 25, 50, and 100\% did not show different degrees of staining or color transfer to adjacent cotton in the multifiber test fabric. The different mordant concentrations were not effective in reducing color bleeding and transfer (Table 4).

Table 4: Mean scores and ANOVA of color change on cotton by four different mordant concentrations of $0,25,50$, and $100 \%$.

\begin{tabular}{|c|c|c|c|c|c|}
\hline Mordant Concentration & $\mathbf{0 \%} \mathbf{( N = 8 )}$ & $\mathbf{2 5 \%}(\mathbf{n}=\mathbf{2 4})$ & $\mathbf{5 0 \%} \mathbf{( n = 2 4 )}$ & $\mathbf{1 0 0} \% \mathbf{( n = 2 4 )}$ & ANOVA ( $\mathbf{n}=\mathbf{8 0})$ \\
\hline Mean & 2.25 & 2.89 & 2.42 & 2.92 & $\mathrm{~F}(3,76)=1.50, \mathrm{p}>.05$ \\
\hline SD & 1.71 & 1.02 & 1.04 & 0.97 & \\
\hline
\end{tabular}

Note: Grade 5-negligible or no color transfer as shown in Gray Scale Step 5, Grade 1-severe color transfer equivalent to Gray Scale Step 1.

However, there were statistically significant differences of staining on cotton by different mordant procedures, $\mathrm{F}(3,76)=3.00$, $\mathrm{p}<.05$, as well as by different heating times, $\mathrm{F}(3,76)=12.11, \mathrm{p}<$ .001 . Pre- and post-mordant procedures ( $M=2.98, \mathrm{SD}=.71 ; \mathrm{M}=2.98$, $\mathrm{SD}=1.12$, respectively) tended to have less color bleeding and staining on cotton than non- and concurrent mordant procedures $(\mathrm{M}=2.25, \mathrm{SD}=1.71 ; \mathrm{M}=2.25, \mathrm{SD}=1.05$, respectively). Pre-and postmordanting procedures could be a better method to prevent color bleeding and color transfer than non-and concurrent mordanting procedures. The $20 \mathrm{~min}$. heating ( $\mathrm{M}=1.98, \mathrm{SD}=.70)$ tended to have more staining on cotton than $10 \mathrm{~min}$. heating ( $\mathrm{M}=2.30, \mathrm{SD}=.86), 15$ min. heating ( $M=2.85, S D=.71)$, and no heating $(M=3.63, S D=1.31)$. Specimens with $20 \mathrm{~min}$. heating would have more natural dye stuffs that stayed stronger on the surface, resulting in more color bleeding and transfer to the cotton in the multifiber test fabrics (Table 5\&6).

Table 5: Mean scores and ANOVA of staining on cotton by four different mordanting procedures: pre-, post-, concurrent, and non-mordanting procedures.

\begin{tabular}{|c|c|c|c|c|c|}
\hline Mordanting Procedures & $\begin{array}{c}\text { Non-Mordanting } \\
\mathbf{( N = \mathbf { 8 } )}\end{array}$ & $\begin{array}{c}\text { Pre-Mordanting } \\
\mathbf{( n = 2 4 )}\end{array}$ & $\begin{array}{c}\text { Concurrent } \\
\text { Mordanting } \\
(\mathbf{n}=\mathbf{2 4})\end{array}$ & $\begin{array}{c}\text { Post-Mordanting } \\
\mathbf{( n = 2 4 )}\end{array}$ & ANOVA (n= 80) \\
\hline Mean & 2.25 & 2.98 & 2.25 & 2.98 & $\mathrm{~F}(3,76)=3.00, \mathrm{p}<.05^{*}$ \\
\hline SD & 1.71 & 0.71 & 1.05 & 1.12 & \\
\hline
\end{tabular}

Note: Grade 5-negligible or no color transfer as shown in Gray Scale Step 5, Grade 1-severe color transfer equivalent to Gray Scale Step 1.

Table 6: Mean scores and ANOVA of color change on cotton by four different times exposed to heat: 0, 10, 15, and 20 min.

\begin{tabular}{|c|c|c|c|c|c|}
\hline Time Exposed to Heat & 0 Min. $\mathbf{( N = 2 0 )}$ & $\mathbf{1 0}$ Min. $(\mathbf{n}=\mathbf{2 4})$ & $\mathbf{1 5}$ Min. $(\mathbf{n}=\mathbf{2 4})$ & $\mathbf{2 0}$ Min. $(\mathbf{n}=\mathbf{2 4})$ & ANOVA (n= 80) \\
\hline Mean & 3.63 & 2.3 & 2.85 & 1.98 & $\mathrm{~F}(3,76)=12.11, \mathrm{p}<.001^{* * *}$ \\
\hline SD & 1.3 & 0.86 & 0.7 & 0.7 & \\
\hline
\end{tabular}

Note: Grade 5-negligible or no color transfer as shown in Gray Scale Step 5, Grade 1-severe color transfer equivalent to Gray Scale Step 1.

\section{Discussion}

The purpose of this study was to examine colorfastness of naturally dyed fabrics using contact dyeing and a natural mordant in relation to different mordant concentrations, mordanting procedures, and times exposed to heat. Overall, results indicate no differences in color change of the contact-dyed specimens by different mordant concentrations and mordanting procedures. Only the time exposed to heat had significant impact on color change on cotton. Longer time exposed to heat could enhance color retention and colorfastness of contact-dyed fabrics to laundering in relation to color change.
Regarding color staining in relation to colorfastness to laundering, the different mordanting procedures and times exposed to heat caused differences in color staining, due to color loss; whereas, the different mordant concentrations did not show differences in staining. Pre- and post-mordanting procedures would enhance bonding of natural dye stuffs with the specimens, resulting in less color bleeding from the contact-dyed fabrics and color transfer to other cotton fabrics. However, the contact-dyed cotton fabrics with longer heating time would cause more bleeding and transfer, mainly due to more colorants remaining on the surface.

Considering the results of colorfastness to laundering in terms of color change and staining, contact dyeing methods with 
$15 \mathrm{~min}$. microwaving and pre- and post-mordanting with vinegar are suggested among the different dyeing methods to produce contact-dyed fabrics with better colorfastness to laundering in relation to color change and staining. In line with previous studies on colorfastness of naturally dyed fabrics, longer times exposed to heat and pre- and post-mordanting procedures were effective to enhance color retention and colorfastness $[1,4]$.

Overall, colorfastness of the contact-dyed cotton fabrics to laundering was poor to moderate. Besides, long exposure in the microwave may waste more energy, although using vinegar, contact method of dyeing, and natural dyes all focused on sustainability. Because colorfastness to laundering was below acceptable AATCC performance standards for applicable apparel products, further research on different dye substances, mordants, and heating methods is needed to improve colorfastness of contact-dyed fabrics to laundering as well as to expand the use of sustainable contactdyeing for consumers and the environment.

\section{Acknowledgement}

None.

\section{Conflict of Interest}

No conflict of interest.

\section{References}

1. Shams-Nateri A, Hajipour A, Dehnavi E, Ekrami E (2014) Colorimetric study on polyamides dyeing with weld and pomegranate peel natural dyes. Clothing and Textiles Research Journal 32(2): 124-135.

2. Haar S, Schrader E, Gatewood BM (2013) Comparison of aluminum mordants on the colorfastness of natural dyes on cotton. Clothing and textiles Research Journal 31(2): 97-108.
3. Kadolph SJ, Casselman KD (2004) In the bag: Contact natural dyes. Clothing and Textiles Research Journal 22(1-2): 15-21.

4. Li YV, Malensek N, Sarkar AK, Xiang C (2016) Colorfastness properties of persimmon dye on cotton and wool fabrics. Clothing and Textiles Research Journal 34(3): 223-234.

5. Ganesan P, Karthik T (2017) Analysis of colour strength, colour fastness and antimicrobial properties of silk fabric dyed with natural dye from red prickly pear fruit. The Journal of The Textile Institute108(7): 11731179.

6. Arroyo-Figueroa G, Ruiz-Aguilar GM, Cuevas-Rodriguez G, Sanchez GG (2011) Cotton fabric dyeing with cochineal extract: influence of mordant concentration. Coloration Technology 127(1): 39-46.

7. Khan AA, Iqbal N, Adeel S, Azeem M, Batool F (2014) Extraction of natural dye from red calico leaves: Gamma ray assisted improvements in colour strength and fastness properties. Dyes Pigment 103: 50-54.

8. Ali NF, El Mohamed RR (2011) Eco-friendly and protective natural dye from red prickly pear plant. Journal of Saudi Chemical Society 15(3): 257-261.

9. Hou X, Chen X, Cheng Y, Xu H, Chen L, Yang Y (2013) Dyeing and UVprotection properties of water extracts from orange peel. Journal of Cleaner Production 52: 410-419.

10. Samanta AK, Agarwal P, Datta S (2007) Dyeing of jute and cotton fabrics using jackfruit wood extract: Part 1-Effects of mordanting and dyeing process variables on colour yield and colour fastness properties. Indian Journal of Fibre \& Textile Research 32: 466-476.

11. Guesmi A, Hamadi NB, Sakli, LF (2012) Dyeing properties and colour fastness of wool dyed with indicaxanthin natural dye. Industrial Crops and Products 37(1): 493-499.

12. Cohen AC, Johnson I, Pizzuto JJ (2010) JJ Pizzuto's Fabric Science (10 ${ }^{\text {th }}$ edn) New York, NY: Fairchild Books, USA.

13. Kadolph SJ (2010) Textiles (11 ${ }^{\text {th }}$ edn), New York, NY: Fairchild Books, USA.

14. Kadolph S J (2007) Quality Assurance for Textiles and Apparel (2nd edn), New York, NY: Fairchild Books, USA. 